\title{
ANALISIS VARIASI TIME REPETITION (TR) TERHADAP SIGNAL TO NOISE RATIO DAN CONTRAST TO NOISE RATIO PADA PEMERIKSAAN MRI CERVICAL T2 WEIGHTED FAST SPIN ECHO (FSE) POTONGAN SAGITAL
}

\section{ANALYSIS OF TIME REPETITION (TR) VARIATION TO SIGNAL TO NOISE RATIO AND CONTRAST TO NOISE RATIO ON CERVICAL MRI EXAMINATION SAGITAL T2 WEIGHTED FAST SPIN ECHO (FSE)}

\author{
Rini Indrati ${ }^{1)}$ Heriansyah $^{2)}$ Wakhrudin $^{3)}$ \\ ${ }^{1,2)}$ Health Polytechnics of Semarang-Indonesia \\ ${ }^{3)}$ Telogorejo Hospital, Semarang \\ e-mail: riniindrati@poltekkes-smg.ac.id
}

\begin{abstract}
Background: Time Repetition (TR) is one parameter that can affect the value of Signal to Noise Ratio (SNR) and Contrast to Noise Ratio (CNR). The purpose of this research is to know the effect of variation of TR value on SNR and CNR on cervical MRI examination with Sagital T2 Weighted Fast Spin Echo sequence and to know the most optimal TR value from the variation of TR value to SNR and CNR on cervical MRI examination with Sagital T2 Weighted Fast Spin Echo.

Methods: The type of this study was experimental study. The study was conducted using MRI 1.5 Tesla at Kasih Ibu Denpasar Hospital. Data were 40 MRI cervical images of sagital Fast Spin Echo from 10 volunteers with four variations of TR ( $2500 \mathrm{~ms}, 3000 \mathrm{~ms}, 3500 \mathrm{~ms}$, and 4000 $\mathrm{ms}$ ). The SNR and CNR values are measured by identifying the Region of Interest (ROI) in the corpus, discus, cerebro spinal fluid (CSF), and medula spinalis regions to obtain the average signals and compared with the mean deviation of the background. Data was analyzed by regression test to know the influence and by Anova test.

Results: The result of the research showed that there was the influence of TR value to SNR and CNR of MRI Cervical Sagital T2 FSE. There was a strong correlation between the variation of TR values with SNR and CNR Cervical with p-value $<0.05$, the optimal TR value obtained in Cervical Sagital T2 FSE anatomical image on MRI 1,5 Tesla modality was $3500 \mathrm{~ms}$.

Conclusion: Time Repetition affected the signal to noise ratio and contrast to noise ratio. TR 3500 ms produced the most optimal cervical MRI image quality.
\end{abstract}

Keywords: time repetition, fast spin echo, T2 weighting, sagital cervical MRI.

\section{PENDAHULUAN}

Salah satu pemeriksaan MRI adalah pemeriksaan Cervical. Pemeriksaan dengan menggunakan MRI mampu menghasilkan citra yang lebih baik dan mempunyai beberapa kelebihan diantaranya dapat memberikan gambaran dengan spatial resolusi yang baik, kontras antar jaringan dengan baik, tanpa radiasi pengion, dan dapat menghasilkan gambaran dengan berbagai potongan (multi planar) yaitu potongan axial, coronal, serta sagital tanpa dilakukan rekonstruksi gambar terlebih dahulu. Untuk jaringan lunak kualitas citra yang dihasilkan menjadi lebih baik dibandingkan dengan modalitas seperti misalnya CT Scann.

Menurut Woodward Peggy (2001), salah satu teknik dalam pencitraan MRI adalah teknik FSE (Fast Spin Echo) dimana teknik ini memiliki keunggulan dibandingkan dengan Spin Echo konvensional, yaitu waktu akuisisi lebih cepat karena terdapat parameter ETL (Echo Train Length) yang aktif pada sekuen ini. Teknik FSE pertama kali dikembangkan pada tahun 1984 oleh Dr. J. Hennig di Universitas Freinberg di Jerman dengan nama RARE (Rapid Acqusition with Relaksation Enhancement), yakni teknik pencitraan dengan waktu scanning cepat, dimana pada sequence ini terdapat banyak echo dalam satu TR atau yang disebut RARE factor. Westbrook (1999) menambahkan, FSE digunakan hampir 40$60 \%$ dalam pemeriksaan MRI. Seiring perkembangan jaman,
FSE diaplikasikan dengan nama Turbo Spin Echo (TSE) dan banyak digunakan untuk pembobotan T2 karena waktu bisa lebih singkat pada Fast Spin Echo.

Kualitas citra pada MRI dipengaruhi oleh beberapa faktor yaitu diantaranya SNR, CNR, spatial resolution dan scan time. SNR (signal to noise ratio) yaitu perbandingan amplitude signal yang diterima oleh koil dengan amplitude noise, CNR (Contras To Noise Ratio) yaitu perbedaan SNR antara organ yang saling berdekatan, spatial resolution yaitu kemampuan untuk membedakan antara 2 titik yang dipisahkan dan dibedakan dengan ukuran voxel dan juga scan time yaitu waktu yang diperlukan untuk melengkapi akusisi data.

TR (Time Repetition) merupakan parameter yang mengontrol jumlah magnetisasi longitudinal yang recovery sebelum RF pulse berikutnya. TR yang panjang memungkinkan full recovery sehingga lebih banyak yang akan mengalami magnetisasi transversal pada RF (Radio Frequeny) pulse berikutnya.

Berdasarkan pengamatan peneliti di RS. Kasih Ibu Denpasar, TR yang digunakan untuk pemeriksaan cervical potongan sagital pada sekuens T2 weighted Fast Spin Echo yaitu $3500 \mathrm{~ms}$, dikarenakan petugas beranggapan dengan menaikkan TR akan membuat pemeriksaan menjadi lama dan kualitas citra menjadi bagus, sedangkan jika menurunkan TR 
menyebabkan waktu pemeriksaan menjadi singkat kualitas citra yang dihasilkan kurang baik.

\section{METODE}

Jenis penelitian adalah adalah eksperimen. Sebanyak 10 sukarelawan sehat di RSU Kasih Ibu Denspasar terlibat dalam penelitian ini. Sampel ditentukan dengan sample size minimal untuk eksperimen sederhana sebesar 10. Data kualitas citra MRI diambil melalui observasi pada empat variasi nilai $T R$ yaitu $2500 \mathrm{~ms}, 3000 \mathrm{~ms}, 3500 \mathrm{~ms}$, dan $4000 \mathrm{~ms}$. Penilaian citra meliputi nilai Signal to Noise Ratio (SNR) dan Contras to Noise Ratio (CNR) pada Corpus, Discus, Medulla spinalis, dan Cerebro Spinal Fluid. Analisa data dilakukan dengan uji korelasi Pearson dan uji regresi untuk mengetahui besar pengaruh TR terhadap SNR dan CNR pada citra Cervical Sagital T2 Fast Spin Echo dilanjutkan uji LSD.

\section{HASIL}

\section{Krakterisitik Sampel}

Penelitian dilakukan terhadap 10 suka relawan berjenis kelamin pria, rentang usia antara 20 tahun sampai dengan 28 tahun dengan berat $55 \mathrm{~kg}$ sampai dengan $80 \mathrm{~kg}$.

Tabel 1. Karakteristik Sampel berdasar Umur

\begin{tabular}{ccc}
\hline Usia & Jumlah & Persentasse \\
\hline 20 & 3 & $30 \%$ \\
23 & 1 & $10 \%$ \\
24 & 5 & $50 \%$ \\
28 & 1 & $10 \%$ \\
\hline & 10 & $100 \%$ \\
\hline
\end{tabular}

Proporsi terbanyak sampel berdasarkan umur adalah 24 tahun yaotu sebesar $50 \%$. Sedangkan karakteristik responden sehat berdasarkan berat badan proporsi terbesar dengan berat badan $60 \mathrm{~kg}$ yaitu sebesar $50 \%$.

Tabel 2. Karakteristik Sampel Berdasar Berat Badan

\begin{tabular}{ccc}
\hline Berat Badan & Jumlah & Prosentase \\
\hline 60 & 5 & $50 \%$ \\
65 & 4 & $40 \%$ \\
80 & 1 & $10 \%$ \\
\hline & 10 & $100 \%$ \\
\hline
\end{tabular}

\section{Hasil Uji Korelasi}

Uji korelasi antara nilai TR dengan Signal to noise Ratio menunjukkan ada korelasi yang kuat dengan koefisien korelasi $\mathrm{r}=0,721$ dengan $\mathrm{p}$ value $<0,001$, dan nilai Determinasi $\mathrm{R}^{2}=$ 0,519

Tabel 3. Korelasi antara nilai TR dengan SNR

\begin{tabular}{cccc}
\hline Variabel & $\mathrm{r}$ & $\mathrm{R}^{2}$ & $\mathrm{p}$ value \\
\hline SNR & 0,721 & 0,519 & $<0,001$ \\
\hline
\end{tabular}

Citra MRI Cervical pada vaiasi Time Repetition seperti pada gambar 1 .
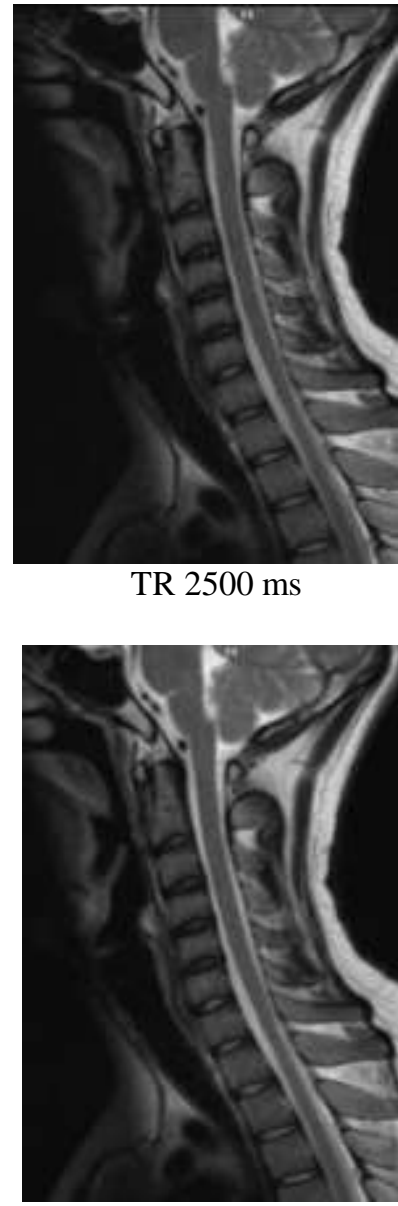

TR $3500 \mathrm{~ms}$
TR $2500 \mathrm{~ms}$

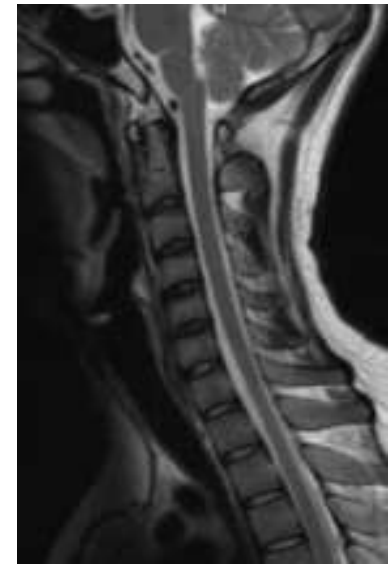

TR $3000 \mathrm{~ms}$

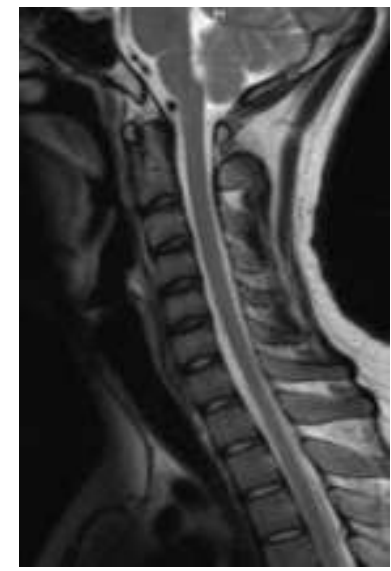

TR $4000 \mathrm{~ms}$
Gambar. 1. Hasil Citra MRI Cervical T2 Weighted Fast Spin potongan Sagital

Uji korelasi antara nilai TR dengan SNR perbagian anatomi seperti pada tabel 4 berikut;

Tabel 4. Hasil uji korelasi TR terhadap CNR per anatomi Cervical

\begin{tabular}{lccc}
\hline \multicolumn{1}{c}{ SNR pada } & $\mathrm{r}$ & $\mathrm{R}^{2}$ & $\mathrm{P}$ value \\
\hline Corpus & 0,688 & 0,473 & \\
Discus & 0,659 & 0,435 & $<0,001$ \\
Medulla spinalis & 0,556 & 0,309 & \\
CSF & 0,734 & 0,538 & \\
\hline
\end{tabular}

Terdapat korelasi yang kuat antara nilai TR dengan SNR Corpus, dengan koefisien korelasi $\mathrm{r}=0,688$ dengan $\mathrm{p}$ value $<0,001$ dan nilai koefisien deteminasi $R^{2}=0,473$. yang artinya 47,3\% SNR dipengaruhi oleh nilai TR sedangkan yang $52,7 \%$ dipengaruhi faktor lain. Terdapat korelasi yang kuat antara variasi nilai TR terhadap SNR Discus, dengan koefisien korelasi $r=0,659$, dengan $p$ value $<0,001$ dan nilai koefisien determinasi $\mathrm{R}^{2}=0,435$ artinya $43,5 \%$ SNR dipengaruhi oleh 
TR sedangkan yang 56,5\% dipengaruhi faktor lain. Terdapat korelasi yang cukup kuat antara variasi nilai TR terhadap nilai SNR Medulla Spinalis, dengan koefisien korelasi $r=0,556$ dengan $\mathrm{p}$ value $<0,001$ dan nilai koefisien determinasi $\mathrm{R}^{2}=$ 0,309. Dari koefisien determinasi menunjukkan bahwa 30,9\% SNR dipengaruhi oleh TR sedangkan yang 69,1\% dipengaruhi faktor lain. Terdapat korelasi yang cukup kuat antara nilai TR terhadap SNR CSF, dengan koefisien korelasi $r=0,734$ dengan $p$ value $<0,001$ dan nilai detrminasi $R^{2}=0,734$ yang artinya $73,4 \%$ SNR dipengaruhi oleh TR sedangkan yang $26,6 \%$ dipengaruhi faktor lain.

Pengaruh variasi nilai TR terhadap CNR pada MRI Cervical irisan Sagital dari rata-rata penghitungan CNR kesepuluh sukarelawan dapat dilihat sebagai berikut;

Tabel 5. Hasil uji korelasi TR terhadap CNR Cervical

\begin{tabular}{cccc}
\hline CNR & $\mathrm{r}$ & $\mathrm{R}^{2}$ & $\mathrm{p}$ value \\
\hline Cervical & 0,592 & 0,350 & $<0,001$ \\
\hline
\end{tabular}

Ada korelasi yang cukup kuat antara variasi nilai TR terhadap CNR Cervical, dengan koefisien korelasi $r=0,592$ dengan $p$ value $<0,001$, dan nilai Determinasi $R^{2}=0,350$ yang artinya 35,0\% CNR dipengaruhi oleh TR sedangkan yang $65,0 \%$ dipengaruhi oleh faktor lain.

Pengaruh variasi nilai TR pada CNR per anatomi Cervical irisan Sagital dari rata-rata penghitungan CNR kesepuluh sukarelawan dapat dilihat pada tabel 7 sebagai berikut;

Tabel 7. Hasil uji korelasi TR terhadap CNR per anatomi Cervical

\begin{tabular}{lccc}
\hline \multicolumn{1}{c}{ SNR pada } & $\mathbf{r}$ & $\mathbf{R}^{\mathbf{2}}$ & p-value \\
\hline Corpus-Discus & 0,335 & 0,112 & $<0,001$ \\
Corpus-CSF & 0,712 & 0,507 & $<0,001$ \\
Discus-CSF & 0,536 & 0,287 & $<0,001$ \\
CSF-Medulla spinalis & 0,533 & 0,284 & $<0,001$ \\
\hline
\end{tabular}

Ada korelasi yang rendah antara variasi nilai TR terhadap CNR Corpus dengan Discus dengan koefisien korelasi $\mathrm{r}=0,335$ dengan $\mathrm{p}$ value $<0,001$ dan nilai deteminasi $\mathrm{R}^{2}=0,112$ yang artinya $11,2 \%$ CNR dipengaruhi oleh TR sedangkan yang $88,8 \%$ dipengaruhi faktor lain. Ada korelasi yang kuat, antara variasi nilai TR terhadap CNR Corpus dengan CSF dengan koefisien korelasi $r=0,712$ dengan $\mathrm{p}$ value $<0,001$ dan nilai determinasi $\mathrm{R}^{2}=0,507$ yang artinya 50,7\% CNR dipengaruhi TR sedangkan yang 49,3\% dipengaruhi faktor lain. Ada korelasi yang cukup kuat antara variasi nilai TR terhadap CNR Discus dengan CSF dengan koefisien korelasi $r=0,536$ dengan $\mathrm{p}$ value $<0,001$ dan nilai determinasi $\mathrm{R}^{2}=0,287$ yang artinya $28,7 \% \mathrm{CNR}$ dipengaruhi oleh TR sedangkan yang $71,3 \%$ dipengaruhi faktor lain. Ada korelasi yang cukup kuat antara variasi TR terhadap CNR CSF dengan Medulla Spinalis dengan koefisien korelasi $\mathrm{r}=$ 0,533 dengan $p$ value $<0,001$ dan nilai determinasi $R^{2}=0,284$ yang artinya $28,4 \%$ CNR dipengaruhi oleh TR sedangkan yang $71,6 \%$ dipengaruhi faktor lain.

Analisis dengan uji beda post hoc untuk mengetahui nilai TR yang optimal terhadap SNR dan CNR Cervical pada pemeriksaan MRI Cervical Sagital T2 Weighted Fast Spin Echo dari masing-masing varias nilai TR.

Uji beda post hoc SNR Cervical Seperti tabel 6 di bawah ini :

Tabel 6. Uji beda Post Hoc LSD test SNR Cervikal

\begin{tabular}{ccccc}
\multicolumn{5}{c}{ Tabel 6. Uji beda Post Hoc LSD test SNR Cervikal } \\
\hline 2500 & 2500 & 3000 & 3500 & 4000 \\
3000 & - & 0,071 & 0,001 & 0,001 \\
3500 & - & - & 0,044 & 0,001 \\
\hline
\end{tabular}

Berdasarkan tabel Post Hoc LSD test SNR Cervical menunjukkan bahwa pada TR 2500 terhadap TR 3000 dengan $\mathrm{p}$ value 0,071 yang artinya tidak ada perbedaan SNR pada TR 2500 terhadap TR 3000, pada TR 2500 terhadap TR 3500 dengan $p$ value 0,001 yang artinya ada perbedaan SNR pada TR 2500 terhadap TR 3500, pada TR 2500 terhadap TR 4000 dengan $\mathrm{p}$ value 0,001 yang artinya ada perbedaan SNR pada TR 2500 terhadap TR 4000, Pada TR 3000 terhadap TR 3500 dengan $\mathrm{p}$ value 0,044 yang artinya ada perbedaan SNR pada TR 3000 terhadap TR 3500, Pada TR 3000 terhadap TR 4000 dengan $p$ value 0,001 yang artinya ada perbedaan SNR pada TR 3000 terhadap TR 4000, Pada TR 3500 dengan TR 4000 dengan $\mathrm{p}$ value 0,061 yang artinya tidak ada perbedaan SNR pada TR 3500 terhadap nilai TR $4000 \mathrm{~ms}$.

Uji beda post hoc SNR Cervical Seperti tabel 8 di bawah ini :

Tabel 8. Uji Beda Post Hoc LSD test CNR Cervical

\begin{tabular}{ccccc}
\hline TR & 2500 & 3000 & 3500 & 4000 \\
\hline 2500 & - & 0,181 & 0,001 & 0,001 \\
3000 & - & - & 0,036 & 0,013 \\
3500 & - & - & - & 0,663 \\
\hline
\end{tabular}

Berdasarkan tabel Post Hoc test CNR Cervical menunjukkan bahwa CNR pada nilai TR 2500 terhadap nilai TR 3000 dengan $\mathrm{p}$ value 0,181 yang artinya tidak ada perbedaan CNR pada nilai TR 2500 terhadap nilai TR 3000, pada nilai TR 2500 terhadap nilai TR 3500 dengan $p$ value 0,001 yang artinya ada perbedaan CNR pada nilai TR 2500 terhadap nilai TR 3500, pada nilai TR 2500 terhadap nilai TR 4000 dengan $p$ value 0,001 yang artinya ada perbedaan CNR pada nilai TR 2500 dengan 4000, Pada nilai TR 3000 terhadap nilai TR 3500 dengan $\mathrm{p}$ value 0,036 yang artinya ada perbedaan CNR pada nilai TR 3000 dengan nilai TR 3500, Pada nilai TR 3000 terhadap nilai TR 4000 dengan $p$ value 0,013 yang artinya ada perbedaan CNR pada nilai TR 3000 dengan nilai TR 4000, Pada nilai TR 3500 dengan nilai TR 4000 dengan $\mathrm{p}$ value 0,663 yang artinya tidak ada perbedaan CNR pada nilai TR 3500 dengan nilai TR 4000. 


\section{DISKUSI}

Pengaruh Pengaturan Parameter Time Repetition Terhadap Signal to Noise Ratio dan Contras to Noise Ratio Pada Pemeriksaan MRI Cervical T2 Weighted Fast Spin Echo Potongan Sagital.

\section{Ditinjau dari SNR}

Dilakukan pengukuran pengaruh variasi parameter Time Repetition terhadap Signal to Noise Ratio Pada Pemeriksaan MRI Cervical T2 Weighted Fast Spin Echo Potongan Sagital, Pengukuran intensitas sinyal dilakukan ROI pada daerah corpus cervical kedua, discus intervertebralis cervical kedua, medulla spinalis sejajar dengan discus intervertebralis cervical kedua, Cerebro Spinal Fluid (CSF) sejajar dengan discus intervertebralis cervical kedua, Sedangkan untuk noise (background) dilakukan ROI diluar dari obyek, Obyek-obyek ini dipilih karena keduanya memiliki proton density yang berbeda sehingga diharapkan akan memberikan intensitas sinyal yang berbeda pula, Software pada komputer akan mengukur sinyal intensity rata-rata pada obyek yang di ROI dan standar deviasi dari noise (background).

Ada korelasi yang kuat antara variasi nilai TR terhadap SNR Cervical, dengan koefisien korelasi $r=0,721$ dengan $\mathrm{p}$ value $<0,001$, dan nilai Determinasi $R^{2}=0,519$ yang artinya $72,1 \%$ SNR dipengaruhi oleh TR sedangkan yang 27,9\% dipengaruhi oleh faktor lain. Ada korelasi yang kuat antara variasi nilai TR terhadap nilai SNR Corpus, dengan koefisien korelasi $\mathrm{r}=0,688$ dengan $\mathrm{p}$ value $<0,001$ dan nilai deteminasi $\mathrm{R}^{2}=0,473$ yang artinya $47, \%$ SNR dipengaruhi oleh TR sedangkan yang 52,7 \% dipengaruhi faktor lain. Ada korelasi yang kuat antara variasi nilai TR terhadap SNR Discus, dengan koefisien korelasi $\mathrm{r}=0,659$, dengan $\mathrm{p}$ value < 0,001 dan nilai determinasi $\mathrm{R}^{2}=0,435$ artinya $43, \%$ SNR dipengaruhi oleh TR sedangkan yang 56,5\% dipengaruhi faktor lain. Ada korelasi yang cukup kuat antara variasi nilai TR terhadap SNR Medulla Spinalis, dengan koefisien korelasi $\mathrm{r}=0,556$ dengan $\mathrm{p}$ value $<0,001$ dan nilai determinasi $\mathrm{R}^{2}$ $=0,309$ yang artinya 30,9 \% SNR dipengaruhi oleh TR sedangkan yang 69,1\% dipengaruhi faktor lain. Ada korelasi yang cukup kuat antara nilai TR terhadap SNR CSF, dengan koefisien korelasi $\mathrm{r}=0,734$ dengan $\mathrm{p}$ value $<0,001$ dan nilai determinasi $\mathrm{R}^{2}=0,734$ yang artinya $73,4 \%$ SNR dipengaruhi oleh TR sedangkan yang 26,6\% dipengaruhi faktor lain.

Berdasarkan hasil tersebut maka dapat dikatakan bahwa nilai TR mempengaruhi SNR, SNR adalah perbandingan antara besarnya amplitudo sinyal dengan amplitude noise, Faktor lain yang mempengaruhi SNR yaitu Densitas proton daerah yang diperiksa dimana semakin tinggi Densitas proton, maka semakin tinggi nilai SNR yang dihasilkan, tebal irisan, dimana semakin besar ukuran ketebalan irisan atau potongan akan menghasilkan voxel yang besar, maka semakin tinggi pula nilai SNR, TE yang panjang dapat mengurangi SNR dan TE yang pendek dapat meningkatkan SNR, Flip Angle yang rendah menghasilkan SNR yang kecil, NEX bertambah maka jumlah data yang tersimpan pada K-Space juga bertamba hubungan lebih rinci yaitu NEX digandakan maka hanya meningkatkan SNR sebesar 1,4, Recieve Bandwidth, semakin kecil Bandwith maka noise akan berkurang dan Penggunaan koil yang dipasang sedekat mungkin dengan obyek. Westbrook (1999). dengan peningkatan nilai TR maka SNR yang dihasilkan semakin tinggi sehingga kualitas citra yang dihasilkan semakin baik

\section{Ditinjau dari CNR}

Menurut Westbrook (1999) CNR adalah perbedaan SNR antara organ yang saling berdekatan, $C N R$ yang baik dapat menunjukkan perbedaan daerah patologis dan daerah sehat.

Ada korelasi yang kuat antara variasi nilai TR terhadap CNR Cervical, dengan koefisien korelasi $r=0,592$ dengan $\mathrm{p}$ value $<0,001$ dan nilai Determinasi $R^{2}=0,350$ yang artinya 59,2\% CNR dipengaruhi oleh TR sedangkan yang 40,8\% dipengaruhi oleh faktor lain. Ada korelasi yang rendah antara variasi nilai TR terhadap CNR Corpus dengan Discus dengan koefisien korelasi $r=0,335$ dengan $\mathrm{p}$ value $<0,001$ dan nilai deteminasi $\mathrm{R}^{2}=0,112$ yang artinya $11,2 \% \mathrm{CNR}$ dipengaruhi oleh TR sedangkan yang $88,8 \%$ dipengaruhi factor lain. Ada korelasi yang kuat, antara variasi nilai TR terhadap CNR Corpus dengan CSF dengan koefisien korelasi $r=0,712$ dengan $\mathrm{p}$ value $<0,001$ dan nilai determinasi $\mathrm{R}^{2}=0,507$ yang artinya 50,7\% CNR dipengaruhi TR sedangkan yang 49,3\% dipengaruhi faktor lain. Ada korelasi yang cukup kuat antara variasi nilai TR terhadap CNR Discus dengan CSF dengan koefisien korelasi $r=0,536$ dengan $p$ value $<0,001$ dan nilai determinasi $\mathrm{R}^{2}=0,287$ yang artinya $28,7 \%$ CNR dipengaruhi oleh TR sedangkan yang $71,3 \%$ dipengaruhi faktor lain. Ada korelasi yang cukup kuat antara variasi nilai TR terhadap CNR CSF dengan Medulla spinalis dengan koefisien korelasi $\mathrm{r}=0,533$ dengan $\mathrm{p}$ value $<0,001$ dan nilai determinasi $\mathrm{R}^{2}=$ 0,284 yang artinya $28,4 \%$ CNR dipengaruhi oleh TR sedangkan yang 71,6\% dipengaruhi faktor lain.

Berdasarkan hasil tersebut maka dapat dikatakan bahwa nilai TR mempengaruhi CNR, Ada beberapa faktor lain yang mempengaruhi CNR yaitu dengan menggunakan kontras media, menggunakan pembobotan sekuens T2, memilih Magnetization Transfer, dan menghilangkan gambaran jaringan normal dengan Spectral Pre-saturation atau menggunakan Short Tau Inversion Recovery (STIR) dan Fluid Attenuated Inversion Recovery (FLAIR) untuk menekan jaringan tertentu, Westbrook (1999), Dengan peningkatan nilai $T R$ maka CNR yang dihasilkan semakin tinggi sehingga kualitas citra yang dihasilkan semakin baik.

Parameter Time Repetition yang Optimal Pada Pemeriksaan MRI Cervical T2 Weighted Fast Spin Echo Potongan Sagital. Kualitas pencitraan MRI sangat mempengaruhi kemampuan untuk memberikan gambaran kontras pada jaringan lunak tubuh. Kualitas ini sangat dipengaruhi oleh faktor alat dan faktor struktur atom penyusun tubuh. Dalam memiliki parameter diupayakan agar gambar yang dihasilkan optimal dengan waktu scanning yang singkat.

Citra yang memiliki kualitas yang optimal disini adalah citra yang dianggap memiliki SNR dan CNR paling baik atau paling tinggi. Berdasarkan perhitungan nilai SNR, maka nilai SNR yang paling tinggi pada pemeriksaan MRI Cervical T2 WI FSE potongan Sagital terdapat pada TR 4000 dengan nilai 
rata-rata SNR Cervical yaitu 115,66. Berdasarkan hasil uji beda Post Hoc SNR cervical pada nilai TR 3500 dengan nilai TR 4000 dengan $\mathrm{p}$ value 0,061 yang artinya tidak ada perbedaan SNR pada nilai TR 3500 terhadap nilai TR 4000, Jadi untuk nilai TR yang paling optimal bisa digunakan TR 3500 dengan alasan dapat mempersingkat waktu pemeriksaan. Sedangkan Untuk nilai CNR pada pemeriksaan MRI Cervical T2 WI FSE potongan Sagital yang paling tinggi terdapat pada TR 4000 dengan nilai rata-rata nilai CNR Cervical yaitu 79,81. Berdasarkan hasil uji beda Post Hoc CNR cervical pada nilai TR 3500 dengan nilai TR 4000 dengan p value 0,663 yang artinya tidak ada perbedaan CNR pada nilai TR 3500 terhadap nilai TR 4000, Jadi untuk nilai TR yang paling optimal bisa digunakan TR 3500 dengan alasan dapat mempersingkat waktu pemeriksaan. Menurut Westbrook (1999) waktu scaning merupakan salah satu faktor yang penting dalam menghasilkan kualitas gambar, waktu scaning dipengaruhi oleh TR sehingga untuk mengurangi waktu scaning dilakukan dengan cara TR sependek mungkin,

\section{SIMPULAN}

Terdapat pengaruh pengaturan Variasi parameter nilai TR terhadap SNR dan CNR pada MRI Cervical sekuen T2 Weighted Fast Spin Echo potongan sagital, Ada korelasi yang kuat antara variasi TR terhadap SNR dengan koefisien korelasi $\mathrm{r}=0,721$ dengan $\mathrm{p}$ value $<0,001$, dan nilai Determinasi $\mathrm{R}^{2}=0,519$ yang artinya $51,9 \%$ SNR dipengaruhi oleh TR sedangkan yang 48,1\% dipengaruhi oleh faktor lain. Ada korelasi yang cukup kuat antara variasi nilai TR terhadap CNR Cervical dengan koefisien korelasi $r=0,592$ dengan $\mathrm{p}$ value $<0,001$, dan nilai Determinasi $R^{2}=0,350$ yang artinya $35,0 \%$ CNR dipengaruhi oleh TR sedangkan yang 65,0\% dipengaruhi oleh faktor lain.

Pengaturan parameter nilai TR yang optimal pada T2 Weighted Fast Spin Echo Sagital pemeriksaan Cervical adalah pada TR $3500 \mathrm{~ms}$, hasil ini Berdasarkan dari uji beda Post Hoc SNR dan CNR pada cervical. untuk SNR Cervical pada TR 3500 terhadap nilai TR $4000 \mathrm{~ms}$ dengan p value 0,061 artinya tidak ada beda SNR pada TR 3500 ms dengan TR 4000 ms. Untuk CNR Cervical pada TR 3500 ms dengan TR $4000 \mathrm{~ms}$ dengan $\mathrm{p}$ value 0,663 yang artinya tidak ada beda CNR pada TR $3500 \mathrm{~ms}$ dengan $4000 \mathrm{~ms}$.

\section{DAFTAR PUSTAKA}

Everty, J, Blink. 2004. Basic MRI Physics, Application Specialist MRI.

Hashemi. Ray.h, and Bradley William g. Jr. 1997. MRI the Basic. William and Wilkins : USA.

Woodward, Peggy, and Wiliam, W. Arrison. 2001. MRI Optimization. A hand on approach. McGraw-Hill. Co : USA.

Woodward, Peggy. and Freimarck, Roger. 1995. MRI for Technologists. McGraw-Hill, Inc: New York, USA.

Martin, dkk. 2012. MRI Comparison of MERGE and Axial T2-Weighted Fast Spin-Echo Sequences for Detection of Multiple Sclerosis Lesions in the Cervical Spinal Cord

Snell, S, Richard. 2006. Anatomi Klinik untuk Mahasiswa Kedokteran. EGC : Jakarta.

Westbrook and Kaut. 1999. MRI In Practice, Second Edition. London: Blackwell Science.
Westbrook, C. 2008. Handbook of MRI technique. Sheridan Books, Inc: United Kingdom.

Woodward, Peggy, and Wiliam, W. Arrison. 2001. MRI Optimization. A hand on approach. McGraw-Hill. Co : USA.

Woodward, Peggy. and Freimarck, Roger. 1995. MRI for Technologists. McGraw-Hill, Inc: New York, USA. 